\title{
Powering ahead
}

\author{
Coal has powered the world, spurring development and the advancement of society; however, the time has come to \\ consign it to the past and find new technology to support development and advancement.
}

A

s the participating countries look towards the COP Climate

Conference this November, it was hoped that coal would be a relic of a different time, but it is still holding on. Coal fuelled the industrial revolution, creating the world we have today. Coal played a key role in economic and societal development and has continued to be seen this way, with few countries succeeding in reducing poverty without expanding coal use ${ }^{1}$.

But with coal came pollution emissions, driving climate change, and particulates, causing health issues. Moving away from this fuel has not been straightforward, and the price of coal needs to reflect the true social cost to accelerate the transition.

Moving away from existing infrastructure requires new technology and investment, which is challenging. Furthermore, there is a need for the will to bear the costs associated with retiring plants before their end of life ${ }^{2}$. But this doesn't always happen, and progress can come with regressions. For example, despite the UK promising to phase out coal by 2024 , when the two remaining plants will be decommissioned, they restarted coal power in early September, with up to $3 \%$ of the national power coming from coal during that time. Still-warm autumn weather reduced wind power generation, and increases in natural gas prices made it more economical to revert to coal.

Since the Paris Agreement in 2015, 44 countries have committed to no new coal projects; additionally, there are a further 40 countries that do not have projects in the pre-construction stage and that could be considered ready to move to no new coal (https://www.e3g.org/publications/ no-new-coal/). In this period, an equivalent of $1,175 \mathrm{GW}$ of coal-powered projects were cancelled. However, there are some countries that still have plans, and six nations account for $82 \%$ of the pre-construction pipeline. For example, Indonesia has committed to no new coal power plants after 2023, but over 100 new coal-powered power plants have been planned before this switch (https://news.mongabay.com/2021/05/ indonesia-says-no-new-coal-plants-from2023-after-the-next-100-or-so/). The commitment to 'new' and renewable energy is welcome; however, there are questions

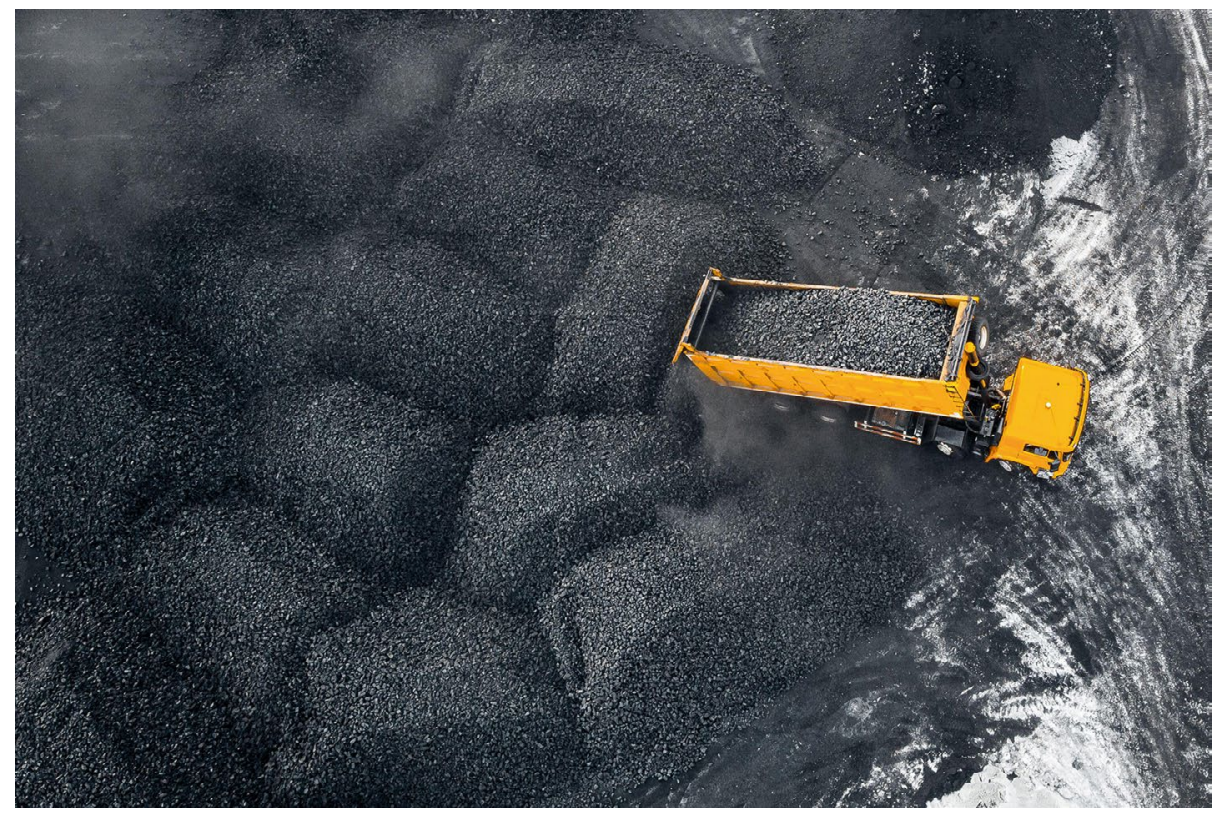

Credit: Evgenii Parilov / Alamy Stock Photo

over what is classified as new as it could include biomass, palm-oil-based biofuel, gasified coal and, possibly, nuclear energy.

Indonesia is not alone with plans for new coal plants, and, as countries are in different stages of development, no plans does not mean that there is a commitment to move away from coal ${ }^{3}$. For example, development in Africa needs financially viable low-carbon technology options so that countries can avoid choosing coal and being locked into high emissions pathways for years to come ${ }^{4}$.

The tension between development and emissions means transitioning from coal needs commitment from government at all levels, as well as commitment from investors and consumers. FirstRand, the largest bank in South Africa, has, like many other financial institutions, announced that no future funding will be available to construct new coal-powered power plants and that funding for new mining projects will be phased out over the next five years.

Mining is the other side of the coal story - Australia, the world's biggest coal exporter, has recently approved the expansion, doubling the capacity, of the Whitehaven coal mine. This is despite the May 2021 ruling from the federal court that there is an obligation to children to consider the harm caused by climate change when making decisions on mining projects. August this year also saw the re-opening of 38 mines in Ordos, Inner Mongolia Autonomous Region, China. These mines, with the capacity to provide over 60 million tonnes of coal, had been closed due to land-use violations but have been re-opened with local government approval.

Power plants in India have been running low on coal in September as the country emerges from COVID-19 restrictions and increased economic activity increases power demands. Coal saw steep declines during the pandemic as energy demands decreased, and it is up to all of us to build on the opportunities of the world ahead and relegate coal to the past and leave it in the ground ${ }^{5}$.

Published online: 30 September 2021 https://doi.org/10.1038/s41558-021-01185-5

\footnotetext{
References

1. Kalkuhl, M. et al. Nat. Energy 4, 897-900 (2019).

. Jewell, J. et al. Nat. Clim. Change 9, 592-597 (2019).

. Jakob, M. et al. Nat. Clim. Change 10, 704-707 (2020).

Steckel, J. C. et al. Nat. Clim. Change 10, 83-88 (2020).

Bertram, C. et al. Nat. Clim. Change 11, 193-196 (2021).
} 